\title{
Kronik Otitis Medialı Hastalarda Kan Grubu Tipleri ile Kolestatom Gelişimi Arasında İlişki Var Mı?
}

\author{
Is There A Relationship Between Blood Group Types and Cholestatoma Development in Patients with Chronic
}

Otitis Media?

Balıkesir Üniversitesi Tip Fakültesi Kulak Burun Boğaz Hastalıkları Ana Bilim Dalı, Balıkesir, Türkiye

Correspondence:

Erhan ARSLAN

Balıkesir Üniversitesi Tip Fakültesi Kulak Burun BoğazHastalkları Ana Bilim Dalı, Balıkesir, Türkiye e-mail:drarslanerhan@hotmail.com

\section{Özet}

ABO ve Rh kan gruplarının kronik otitis media'lı hastalarda kolesteatom gelişimi ve hastalık ciddiyeti ile ilişkisinin incelenmesi Kliniğimizde 2013-2020 yılları arasında kronik otit nedeniyle ameliyat edilen 149 hastanın ve normal toplumla karşılaștırılması amacıyla kronik otit öyküsü olmayan 200 hastanın dosyaları retrospektif olarak incelendi. Hastalar grup 1: kolesteatomlu kronik otit, grup 2: kolesteatomsuz kronik otit ve grup 3: kontrol grubu olarak sinıflandırıldı. Her hasta için yaş, cinsiyet, kan grubu verileri incelenerek karşılaștırıldı. Kolesteatom tespit edilen hastaların orta kulak risk indeksleri (OKRI) ve kolesteatom evrelemeleri (KE) kaydedildi ve bu değerler ile kan grupları arasındaki ilişki incelendi. Grup 1'de 68 grup 2'de 81 hasta ve grup 3' de 200 hasta vardı. Gruplar arasında yaş ortalamaları açısından fark yoktu. Grup l'de bayan hasta oranı grup 2 ve kontrol grubuna göre daha düşüktü (p:0,021). Grup 1'de O kan grubu, grup 2'ye ve kontrol grubuna göre anlamlı derecede düşük, A kan grubu anlamlı derecede yüksekti (p:0,047). Diğer kan grupları açısından gruplar arasında anlamlı fark görülmedi (p>0,05). Kolesteatomlu hastalarda OKRİ skorları ve KE açısından kan grupları arasında anlamlı fark görülmedi (sırasıyla p:0,149, p:0,157). Kan grupları farklılıklarının birçok hastalık gelişiminde risk faktörü olabileceğine yönelik çalışmalar yapılmıștır. Biz de yaptığımız çalışmada, kolesteatom gelişimi açısından O kan grubuna sahip bireylerin daha az risk, A kan grubuna sahip bireylerin ise daha yüksek risk taşıdıkların tespit ettik. Bu sonuçlar 1şı̆̆ında kronik otitli hastalarda kolesteatom gelişimi açısından kan grupları farklılıklarının, hastaların takiplerinde bir risk faktörü olarak göz önünde tutulmasının faydalı olabileceğini düşünmekteyiz. Anahtar Kelimeler: Kemik İliği Metastazı, Solid Tümör, Anemi, Trombositopeni

\section{Abstract}

Investigation of the relationship of $\mathrm{ABO}$ and $\mathrm{Rh}$ blood groups with cholesteatoma development and disease severity in patients with chronic otitis media. The files of 149 patients who were operated for chronic otitis in our clinic between 2013-2020 and in order to compare them with the normal population, 200 patients without a history of chronic otitis were investigated retrospectively. The patients were classified as group 1: chronic otitis media with cholesteatoma, group 2: chronic otitis media without cholesteatoma, and group 3: control group. Age, gender, and blood group data were analyzed and compared for each patient. Middle ear risk index (MERI) and cholesteatoma staging (CS) of patients with cholesteatoma were recorded and the relationship between these values and blood groups was examined. Group 1 had 68 patients, group 2 had 81 patients, and group 3 had 200 patients. There was no difference between the groups in terms of mean age. The ratio of female patients in group 1 was lower than group 2 and control group $(\mathrm{p}=0.021)$. In group 1 , blood group $\mathrm{O}$ was significantly lower and blood group A was significantly higher than group 2 and control group $(\mathrm{p}=0,047)$. There was no significant difference between the groups in terms of other blood groups $(\mathrm{p}>0.05)$. In patients with cholesteatoma, there was no significant difference between blood groups in terms of MERI scores and CS ( $p=0.149, p=0.157$, respectively). Studies have been performed to show that differences in blood groups may be risk factors in the development of many diseases. In our study, we found that individuals with blood group $\mathrm{O}$ have less risk and individuals with blood group A have a higher risk of developing cholesteatoma. In the light of these results, we think that it may be beneficial to consider differences in blood groups in terms of the development of cholesteatoma in patients with chronic otitis media as a risk factor in the follow-up of patients.

Keywords: Cholesteatoma; chronic otitis media; blood groups

Received 16.09.2021 Accepted 09.11.2021 Online published 10.11.2021 


\section{Giriş}

Hastalıkların oluşumunda farklı birçok etiyolojik faktör ve patolojik mekanizma rol almaktadır. $\mathrm{Bu}$ amaçla hastalıkların nedenleri araştırılırken ırk, yaş, cinsiyet, anatomik, genetik veya akkiz faktörler sorgulanmakta ve hastalar arasinda bulunabilecek farklıliklar incelenmektedir. Toplumdaki bireylerin farkl1lıklarının belirlenmesinde incelenen değişkenlerden birisi de kan gruplarıdır. Kan grupları en s1k $\mathrm{ABO}$ ve $\mathrm{Rh}$ kan grubu sistemleri ad1 verilen kompleks karbonhidrat molekülleri ile sınıflandırılmaktadır. Kan grubu antijenleri eritrositlerde, lökositlerde, trombositlerde, plazma proteinlerinde ve çeşitli doku ve hücre yüzey enzimlerinde bulunmaktadırlar. Ayrıca tükürük, ter, anne sütü, mide salgıları, idrar ve seminal sıvı gibi vücut salgilarında çözünür formda (sekretuvar) bulunurlar (1). Farklı dokularda yaygın olarak bulunması sebebiyle önceki çalışmalarda kan grubu farklılıklarının enfeksiyon, kanser, pihtılaşma bozuklukları gibi bazı farklı hastalık gruplarında hastalık oluşum ve gelişim süreçleri ile olan ilişkisine yönelik çalışmalar yapılmış ve anlamlı sonuçlar rapor edilmiştir (2).

Literatür taramamıza göre kulak burun boğaz hastalıklarından tükürük bezi tümörleri (3), baş boyun tümörleri (4), işitme kaybı (5), effüzyonlu otitis media (EOM) (6), rekürren akut otitis media (7), gibi hastalıklarla kan grupları ilişskisi incelenmiş fakat kronik otitis media ve kolesteatom ile $\mathrm{ABO}$ ve $\mathrm{Rh}$ kan grupları ilişkisini inceleyen çalışma bulunmamaktadır.

Kolesteatom; konjenital, enfeksiyöz, anatomik nedenler gibi birçok farklı patogenez ile ilişkilendirilen fakat etiyopatogenezi tam olarak ortaya konulamamış bir hastalıktır. Histolojik olarak benign olmasına karşın lokal invazyon özellik gösterir ve önemli morbiditelere ve bazen mortalitelere yol açabilir (8). Özellikle de kronik otitin majör bir komplikasyonu olması ve kronik otit cerrahisi sonrası nüks etme potansiyeli olması sebebiyle hastaların takip edilme gereksinimi olan kolesteatom vakalarında risk faktörlerinin belirlenmesi önem arz etmektedir.
$\mathrm{Bu}$ çalışmada, önceki çalışmalarda diğer birtakım hastalıkların gelişimi ve seyri açısından risk faktörü olarak etkisi gösterilmiş olan $\mathrm{ABO}$ ve $\mathrm{Rh}$ kan grubu tiplerinin kolesteatomlu ve kolesteatomsuz kronik otitis media hastalarındaki bulunma oranlarının birbirileri ile ve normal toplumla karşılaştırılması ve kan grubu tipine göre kolesteatomun yayginlığ 1 ve kolesteatom evresinin değerlendirilmesi amaçlanmıştır.

\section{Gereç ve Yöntemler}

Çalışmamıza 2013-2020 yılları arasında kliniğimizde kronik otitis media nedeniyle ameliyat edilen 18-75 yaşları arasında hastalar dâhil edildi. Hastalar ameliyat esnasında tespit dilen kolesteatom varlığına göre grup 1: kolesteatomlu kronik otit, grup 2: kolesteatomsuz kronik otit olarak siniflandi. Ayrıca normal popülasyonla olan farklilıkları incelemek amaciyla kontrol grubu (grup 3) olarak kliniğimize bașvuran ve kronik otit ve başka bir kronik hastalığ 1 bulunmayan hastalar çalışmaya dâhil edildi. Tüm hastaların yaş, cinsiyet ve kan grubu verileri retrospektif olarak incelenerek kaydedildi. Kolesteatom tespit edilen hastalarda hastalığın ciddiyeti ile evresinin kan grupları ile ilişkisinin incelenmesi amaciyla hastaların orta kulak risk indeksleri (OKRİ, Middle ear risk index) (9) ve kolesteatom evrelemeleri (KE, STAM evreleme sistemi) (10) belirlendi. Kardiyovasküler hastalık, kanser, nörolojik hastalık, kronik obstrüktif akciğer hastalığı, romatizmal patoloji, inflamatuvar barsak hastalığı öyküsü gibi kronik hastalığı olanlar ve incelenen verilerinde eksiklik olan hastalar çalışmaya dâhil edilmedi. Çalışma için 2020/105 karar numarası ile yerel etik kurul onayı alındı. Çalışmamız Helsinki Deklarasyonu'na uygun olarak gerçekleştirilmiştir.

\section{İstatistiksel analiz}

Tüm istatistiksel analizler SPSS v 20.0 ile yapıldı. Grup verilerinin normallik varsayımı kolmogorov smirnov testi ile yapıldı. Sürekli değişkenler ortalama ( \pm standart sapma) veya ortanca (minimum-maksimum) olarak, kategorik değişkenler sayı ve yüzde olarak betimlendi. Kategorik değişkenlerin gruplar 
aras1 s1kl1k verileri Ki-kare testi ile karşılaştırıldı. Sürekli değişkenlerin gruplar arası karşılaştırmasında Kruskall Wallis testi ve Mann-Whitney U testi kullanıldı. $\mathrm{P}<0,05$ değeri istatistiksel olarak anlamlı kabul edildi. G*Power 3.1.9.4 programı ile örneklem büyüklüğü hesaplandı.

\section{Bulgular}

Örneklem büyüklüğü hesaplamasında 0,05 önemlilik düzeyi, \%80 güç ve 0,2 etki büyüklügüü ile toplam örneklem sayıs 341 olarak bulundu. Çalışmamızda da kronik otitis media nedeniyle ameliyat edilen ve çalışmaya dâhil edilme kriterlerini karşıllayan hastalardan birinci grupta 68 , ikinci grupta 81 ve kontrol grubu olan üçüncü grupta 200 hasta olmak üzere toplam 349 hasta vardı. Hastaların demografik verileri Tablo 1'de özetlenmiştir. Yaş ortalamaları açısından gruplar arasında anlamlı fark saptanmazken (p:0,580) cinsiyet açısından değerlendirildiğinde grup 1'deki kadın hasta sayısı grup 2'ye ve kontrol grubuna göre anlamlı derecede düşük izlendi (p:0,021).

Tablo 1. Gruplardaki hastaların demografik verileri

\begin{tabular}{ccccc}
\hline & Grup 1 (n:68) & Grup 2 (n:81) & Grup 3 (n:200) & $p$ \\
\hline $\begin{array}{c}\text { Cinsiyet n(\%): } \\
\text { Erkek/ }\end{array}$ & $42(61,8) /$ & $33(40,7) / 48(59,3)$ & $89(44,5) /$ & $\mathbf{0 , 0 2 1 \dagger}$ \\
Kadın & $26(38,2)$ & & $111(55,5)$ & \\
& & & \\
Yaş (yıl)* & $41,05 \pm 15,88$ & $40,72 \pm 14,74$ & $39,23 \pm 15,03$ & $0,580^{*}$ \\
\hline †: Ki-kare testi, $\ddagger$ : Kruskall Wallis testi, *: Ortalama \pm standart sapma olarak sunulmuştur. & \\
\hline
\end{tabular}

Gruplara göre kan grubu dağılımları incelendiğinde; O kan grubu, grup 1'de grup 2'ye ve kontrol grubuna göre anlamlı düzeyde düşük, A kan grubunun ise anlamlı derecede yüksek olduğu saptandı (p:0,047) (Tablo 2). Diğer kan grupları açısından yapılan değerlendirmelerde gruplar arasında anlamlı fark görülmedi $(\mathrm{p}>0,05)$.

Tablo 2. Gruplardaki hastaların kan grubu dağılımları

\begin{tabular}{ccccc}
\hline Kan grubu n(\%) & Grup 1 (n:69) & Grup 2 (n:81) & Grup 3 (n:200) & p $^{*}$ \\
\hline A & $40(58,8)$ & $30(37,0)$ & $82(41,0)$ & \\
B & $14(20,6)$ & $20(24,7)$ & $36(18,0)$ & \\
AB & $4(5,9)$ & $5(6,2)$ & $18(9,0)$ & \\
O & $10(14,7)$ & $26(32,1)$ & $64(32,0)$ & $\mathbf{0 , 0 4 7}$ \\
Rh: (+/-) & $63 / 5$ & $77 / 4$ & $185 / 15$ & 0,733 \\
\hline
\end{tabular}

Kolesteatomlu hastalarda hastalığın ciddiyeti ve kolesteatomun yaygınlığının kan grubu ile olan ilişkisinin incelenmesinde, OKRİ değerleri ve kolesteatom evreleri ile kan grupları arasında anlamlı bir ilişki izlenmedi (sirasiyla p:0,149, p:0,157) (Tablo 3).

Tablo 3: Kolesteatom tespit edilen hastaların kan grubu dağılımlarına göre Orta Kulak Risk İndeksi ve Kolesteatom Evrelemeleri

\begin{tabular}{|c|c|c|c|c|c|}
\hline \multicolumn{5}{|c|}{ Kan grubu } & \multirow[b]{2}{*}{$p^{\dagger}$} \\
\hline & A & B & AB & O & \\
\hline OKRIं* & $7,98 \pm 1,12$ & $8,43 \pm 0,75$ & $9,00 \pm 0,82$ & $8,50 \pm 0,97$ & 0,149 \\
\hline $\mathbf{K E}^{* *}$ & $2(1-4)$ & $2(2-3)$ & $3(2-3)$ & $2(1-3)$ & 0,157 \\
\hline \multicolumn{6}{|c|}{ Rh Grubu } \\
\hline & Rh (+) & Rh (-) & & & $p^{\ddagger}$ \\
\hline OKRIं* & $8,24 \pm 1,05$ & $7,80 \pm 0,84$ & & & 0,227 \\
\hline KE** & $2(1-4)$ & $3(2-3)$ & & & 0,253 \\
\hline
\end{tabular}


KE: Kolesteatom evresi, OKRI: Orta kulak risk indeksi, *: ortalama \pm standart sapma ve **: ortanca (minimummaksimum) olarak sunulmuştur. $†$ : Kruskall Wallis testi, $\ldots$ : Mann Whitney U testi.

\section{Tartışma}

Hastalıkların

etiyopatogenezinin aydınlatılmasındaki önemli basamaklardan biri hastalar arasındaki fizyolojik farklılıkların tespiti ve bu farkl111kların patolojik süreçlerin gelişimine etkisinin saptanmasıdır. Dolayısıyla hastaların sağlıklı insanlara göre farklilıklarının belirlenmesi ve bu farklilıkların hastalık patogenezine olan etkisinin incelenerek risk faktörlerinin belirlenmesi önem arz etmektedir. İnsanlar arasındaki temel farklılık parametrelerinin en bilinenlerinden birisi de kan grubu tipleridir. Önceki çalışmalarda kan grubu farklılıklarının hemolitik hastalıklar, dolaşım bozuklukları, bilişsel bozukluklar, bakteri, virüs ve parazit enfeksiyonları, kanserler, hipertansiyon, hiperlipidemi ve diyabetes mellitus gibi metabolik hastalıklarla ilişkilendirilebileceği gösterilmiştir (1). Fakat literatür taramamıza göre kolesteatom varlığı ve hastalığın ciddiyeti ile kan grubu tiplerinin ilişkisini inceleyen bir çalışma bulunmamaktadır.

Kolesteatom orta kulak boşluğu ve/veya mastoid kavitede keratinize yassı epitel, subepitelyal bağ doku ve keratin debris birikimi ile oluşan ve genellikle etrafında inflamasyonun eşlik ettiği bir kitlesel lezyondur (10). Histolojik olarak benign olmasına karşın lokal invazyon özelliği olup kemikçik hasarı ile işitme kaybı, labirentin bölge hasarı ile denge problemleri ve sensörinöral işitme kaybı, fasial sinir paralizisi, dura hasarı gibi intrakraniyal komplikasyonlara neden olabilmektedir $(8,11)$. Kolesteatomun medikal tedavisi bulunmadığından cerrahi olarak temizlenmesi tek tedavi yöntemidir. Etiyopatogenezi tam olarak ortaya konulamamakla birlikte gelişimi açısından invajinasyon teorisi, bazal hücre hiperplazi teorisi, squamöz metaplazi teorisi, epitelyal invazyon teorisi gibi farklı teorik mekanizmalar tanımlanmıştır

Çalışmamız sonucunda yapılan istatistiksel analizlerde $\mathrm{O}$ kan grubunun kolesteatomlu kronik otit hastalarında, normal popülasyona ve kolesteatomsuz kronik otit hastalarına göre anlamlı derecede daha az olduğunu, A kan grubunun ise normal popülasyona ve kolesteatomsuz kronik otit hastalarına göre anlamlı derecede fazla olduğunu tespit ettik.

Kan grubu belirteçleri olarak kabul edilen 30 'dan fazla protein ve şeker vardır, ancak en antijenik olanları 1901 yılında Landsteiner tarafından tanımlanmış olan 9q34 ve $1 \mathrm{p} 36$ kromozomunda bulunan $\mathrm{ABO}$ ve $\mathrm{Rh}$ (D) sistemine ait belirteçlerdir. Fenotiplerin kolay tanımlanması nedeniyle $\mathrm{ABO}$ sistemi en çok araştırılan eritrosit antijen sistemidir. $\mathrm{ABO}$ ve $\mathrm{Rh}$ kan gruplarının dağ 1 lımı bölgeler ve ırklar arasında değişebilir fakat kan gruplarının kalıtımı herhangi bir çevresel faktörden etkilenmez (13). Dolayısıyla coğrafyaya göre de kan gruplarının incelenmesi ve hastalıklarla ilişkisinin ortaya konulması daha objektif sonuçlar vermektedir. Genel olarak dünyada en sık olarak karşımıza çıkan kan grubu 0 ve A olarak belirlenmiş̧ir. Birçok toplumda $\mathrm{O}$ kan grubu en sik görülen kan grubu iken Avrupa'da A kan grubu daha sı izlenmektedir (14). Çalışmamızdaki kontrol grubu hastalarında tespit ettiğimiz kan grubu dağılımları Türkiye geneli ve Balıkesir ilinde yapılan önceki çalışmalarla benzer oranlarda görülmekteydi $(15,16)$.

Kan grupları eritrosit yüzeylerinde bulunan antijen ve serumda bulunan antikor durumuna göre tanımlanırlar. Örneğin; A kan grubuna sahip bireyler eritrosit yüzeylerinde A antijeni taşıllarken serumlarında anti-B antikoru bulundururlar, B grubuna sahip bireyler eritrosit yüzeyinde $B$ antijeni ve serumda anti$\mathrm{A}$ antikoru, $\mathrm{AB}$ kan grubuna sahip bireyler eritrosit yüzeyinde hem $\mathrm{A}$ hem de $\mathrm{B}$ antijeni taşırken serumlarında antikor taşımazlar, $\mathrm{O}$ kan grubuna sahip bireyler ise eritrosit yüzeyinde antijen taşımazken serumlarında hem anti-A hem de anti-B antikorları taşırlar (14). Bu özellik sayesinde, anti-A ve anti-B antikorları taşıyan $\mathrm{O}$ kan grubu bireylerin, $\mathrm{A}$ ve $B$ antijenlerine benzeyen yüzey antijenleri taşıyan birçok patojene karşı doğal bir direnç oluşturduğu ve enfeksiyonlara karşı daha dayanıklı oldukları öne sürülmüştür (17). Bu açıdan bakıldı ̆̆ında kolesteatom gelişiminde suçlanan patolojilerden birisi olan tekrarlayan 
orta kulak enfeksiyonları sebebiyle kan grubu farklılıklarının hastalık gelişiminde bir etken olabileceği düşünülebilir. Kronik otit zemininde kolesteatom gelişim sürecinde en sık karşılaşılan organizmalar olan pseudomonas aeruginosa, staf aureus ve koagülaz negatif stafilokoklar üzerine yapılan çalışmalar incelendiğinde de bu görüşü destekler çalışmalar yayınlanmıştır (18). Nurjadi ve ark. kan grubu O/sekretuvar (sekretuvar $=\mathrm{A}$ ve $\mathrm{B}$ antijenlerini ve bunların öncülü olan $\mathrm{H}$ antijenlerini eritosit yüzeyleri dişında vücut sivılarında da bulunduran kişiler) olanların boğaz florasında S. Aureus taşıyıcılık riskinin daha az olduğunu ve böylece O/sekretuvar grubun S. Aureus a karşı koruyucu olduğunu vurgulamışlardır (19). Bunun yanında P. Aeruginosa ve koagülaz negatif stafilokok enfeksiyonlarına, A ve B kan grubu taşıyanlarda $\mathrm{O}$ kan grubu taşıyanlara göre daha yüksek oranda gözlendiği önceki yayınlarda gösterilmiştir (20-22). Dolayısıyla bu açıdan bakıldığında çalışmamızda gözlendiği gibi $\mathrm{O}$ kan grubuna sahip bireylerin kolesteatom gelişimi açısından enfeksiyon bağlamında daha az riske sahip olduğu makul bir yaklaşım olarak düşünülebilir.

Inflamatuvar olarak hastalık gelişim riskleri değerlendirildiğinde ise bir meta-analiz çalışmada A kan grubuna sahip bireylerin myokard infarktüsü, periferik damar hastalıkları, venöz tromboemboli ve inme açısından daha yüksek riske sahip oldukları ve bunun bir nedeni olarak da A kan grubunda artmış inflamasyon ve adezyonun olabileceğini belirtilmiştir (23). Bir diğer çalışmada inflamasyon ve adezyonu azaltan soluble intercellular adhesion molecule-1 (sICAM-1) ve soluble P-selectin (sP-selectin) moleküllerinin A kan grubunda en az $\mathrm{O}$ kan grubunda en fazla düzeyde bulunduğu tespit edilmiş ve bunun da $\mathrm{O}$ kan grubunda azalmış, A kan grubunda artmış inflamasyon ve adezyona neden olabileceği belirtilmiştir (24). Kolesteatom patogenezindeki inflamatuvar sürecin önemi ve hastalığın ilerlemesinde çevre dokulara olan adezyon özelliği düşünüldügünnde, kolesteatomun inflamasyona karşı daha dirençli olarak raporlanan $\mathrm{O}$ kan grubunda daha az ve inflamatuvar hastalıkların daha fazla görüldüğü A grubunda daha fazla görülmesi bu patogenezi desteklemektedir.

Kolesteatom gelişimi açısından en önemli risk faktörlerinden birisi de orta kulak havalanma bozukluklarıdır ve bu durum aynı zamanda EOM gelişimi için de geçerlidir (12,25). Mortensen ve ark. EOM gelişiminde A kan grubuna sahip bireylerin $\mathrm{O}$ kan grubu sahip bireylere göre 1,49 kat daha riskli olduklarını tespit etmişlerdir (6). Wiesen ve ark. otitis media gelişimi ile ABO kan grubu türleri arasındaki ilişkiyi inceledikleri çalışmalarında, O kan grubunu rekürren akut otitis media için koruyucu bir faktör olarak belirlerken A kan grubu bireylerin kronik EOM için diğer kan gruplarına göre daha yüksek risk taşıdıklarını belirtmişlerdir (7). Apostolopoulos ve ark. O kan grubunun EOM gelişimine karşı koruyucu rolü olduğunu ve AB grubunun ise aksine EOM gelişimi için diğer kan gruplarına göre daha yüksek risk taşıdığını belirtmişlerdir (26). Bunun sebebi olarak da $\mathrm{AB}$ kan grubu için artmış, $\mathrm{O}$ kan grubu için azalmış enfeksiyon riskinin olduğunu belirtmişlerdir. Orta kulaktaki havalanma bozukluğunun EOM ve kolesteatom gelişimi için ortak risk faktörü olduğunu düşünürsek, benzer bir şekilde çalışmamız sonucunda da kolesteatom gelişimi açısından $\mathrm{O}$ kan grubunun daha az risk, A kan grubunun daha fazla risk taşımakta olması EOM ile yapılan önceki çalışmaların sonuçlarını desteklemektedir. Her ne kadar çalışmamız tasarımında kolesteatom etiyolojisi açısından EOM öyküsü sorgulanmamış olsa da, kolesteatom gelişimi açısından EOM hastalarının takiplerinde kan grubu farklılıklarının göz önünde bulundurulmasının faydalı olabileceğini düşünmekteyiz.

Kolesteatom gelişim sürecinde açığa kavuşmamış noktalardan birisi ise, orta kulakta negatif basınç nedeniyle kulak zarında retraksiyon cebi gelişen hastaların bir k1smında kolesteatom gelişirken bir kısmında neden gelişmediğidir. Bu durumun epidermisi oluşturan keratinosit hücrelerinin fizyolojik turn over' inda meydana gelen proliferasyon, maturasyon ve apoptozis mekanizmalarının etkilenmesinden dolayı olduğu hipotezi öne sürülmüştür $\quad(27,28)$. Kolesteatom dokusundaki keratinize yassı epitelin normal 
cilt epiteline göre proliferasyon kapasitesinde artış ve bu epitelin orta kulak ve mastoide migrasyonu, kolesteatom dokusu örneklerinde proliferasyon markerlarının ve tümör ilişkili genlerin arttığının gösterilmesi bu hipotezi desteklemektedir $(27,28)$. A kan grubu bireylerde patolojik hücrelerin adezyon ve migrasyon potansiyellerinin arttığ 1 , $\mathrm{O}$ kan grubu bireylerde ise tam tersine azaldığ1 gösterilmiştir (29). Bunun sebebi olarak da patolojik dokuların A antijenine benzer yüzey antijeni taşıması sebebiyle immün sistemden kaçışı olabileceğini vurgulanmıştır. Bu açıdan bakıldığında da kan grubu farkl1lıklarının epitel dokusundaki adezyon ve migrasyon özelliklerindeki değişimlerle birlikte olabilmesi sebebiyle, retraksiyon cebi veya havalanma bozukluğu olan kulaklarda kolesteatom gelișimi açısından kan gruplarının risk ya da koruyucu bir faktör olabileceği ve hasta takiplerinde göz önünde bulundurulması fayda sağlayabilir.

Çalışmamızda kolesteatom tespit edilen hastalarda hastalığın ciddiyeti ve kolesteatomun evresi açısından hastaların STAM evreleme sistemi ve MERI değerleri incelenmiştir. Fakat iki değer açısından da kan grupları arasinda anlamlı farklılık saptanamamıştır. $\mathrm{Bu}$ bulgular kolesteatom gelişimi açısından kan gruplarının ayırıcı bir faktör olabileceği fakat kolesteatom gelişen hastalarda hastalığın seyri açısından kan gruplarına göre bir farklılık olmadığı ve hastalık seyrinde diğer farklı etiyolojik faktörlerin göz önünde bulundurulmasının gerektiğini düşünmekteyiz.

\section{KAYNAKLAR}

1. Ewald DR, Sumner SC. Blood type biochemistry and human disease. Wiley Interdiscip Rev Syst Biol Med. 2016;8:517-35.

2. Garratty G. Blood groups and disease: a historical perspective. Transfus Med Rev. 2000;14:291-301.

3. Pinkston JA, Cole P. ABO blood groups and salivary gland tumors (Alabama, United States). Cancer Causes Control. 1996;7:572-4.

4. Bakhtiari S, Far SM, Alibakhshi Z et al. Salivary Secretor Status of Blood Group Antigens in Patients with Head and Neck Cancer. Open Access Maced J Med Sci. 2019;7:373-7.

5. Chen WW, Chow KT, McPherson B. ABO Blood Group and Cochlear Status: Otoacoustic Emission Markers. Ear Hear. 2018;39:555-62.
Çalışma grubundaki hasta sayımızın düşük olması, kolesteatom gelişmiş hastalarda hangi patolojik mekanizmanın hastalığa sebep olduğunun aydınlatılamamış olması, kolesteatom gelişimi ve süresi açısından yeterli verilerin elde edilememiş olması çalışmamızdaki kısıtlayıcı faktörlerdendir. Ayrıca kontrol hastalarında ve kronik otitli hastalarda ileride gelişebilmesi muhtemel olan kolesteatomun öngörülemez olması da bir kısitlama olarak değerlendirilmelidir. $\mathrm{Bu}$ açıdan daha fazla sayıda hastanın ve sağlıklı gönüllünün katılımının sağlandığı geniş kapsamlı prospektif planlanmış çalışmalar konu hakkında daha aydınlatıcı veriler sağlayacaktır.

\section{Sonuç}

Çalışmamız sonucunda $\mathrm{O}$ kan grubuna sahip bireylerin kolesteatom açısından daha az risk, A kan grubuna sahip bireylerin ise daha yüksek risk taşıdıklarını tespit ettik. $\mathrm{Bu}$ bulgularla kronik otit ve eşlik eden retraksiyon, adezyon veya sik enfeksiyon şikâyeti olan ve timpanoplasti sonrası nüks veya rezidü kolesteatom açısından risk taşıyan bireylerin takiplerinde kan gruplarının da bir risk faktörü olarak göz önünde tutulmasının faydalı olabileceğini düşünmekteyiz. Ancak ileri çalışmalarda daha geniş kapsamlı gruplarda ve toplumlarda, farklı kan grubu alt tiplerinin de incelendiği çalışmalara ihtiyaç vardir.

6. Mortensen EH, Lildholdt T, Gammelgård NP et al. Distribution of $\mathrm{ABO}$ blood groups in secretory otitis media and cholesteatoma. Clin Otolaryngol Allied Sci. 1983;8:263-5.

7. Wiesen BM, Hafrén L, Einarsdottir E et al. ABO Genotype and Blood Type Are Associated with Otitis Media. Genet Test Mol Biomarkers .2019;23:823-7.

8. Kuo CL. Etiopathogenesis of acquired cholesteatoma: prominent theories and recent advances in biomolecular research. Laryngoscope. 2015;125:234-40.

9. Becvarovski Z, Kartush JM. Smoking and tympanoplasty: implications for prognosis and the Middle Ear Risk Index (MERI). Laryngoscope. 2001;111:1806-11. 
10. Yung M, Tono T, Olszewska E et al. EAONO/JOS Joint Consensus Statements on the Definitions, Classification and Staging of Middle Ear Cholesteatoma. J Int Adv Otol. 2017;13:1-8.

11. Kuo CL, Liao WH, Shiao AS. A review of current progress in acquired cholesteatoma management. Eur Arch Otorhinolaryngol. 2015;272:3601-9.

12. Semaan MT, Megerian CA. The pathophysiology of cholesteatoma. Otolaryngol Clin North Am. 2006;39:1143-59.

13. Ozyurt K, Oztürk $\mathrm{P}$, Gül $\mathrm{M}$ et al. ABO blood groups, Rhesus factor, and Behçet's disease. Acta Dermatovenerol Alp Pannonica Adriat. 2013;22:63-4.

14. Daniels G. (2013), ABO, H. Lewis systems. In Human Blood Groups, Daniels G. Ed. 3rd ed. Wiley-Blackwell:Chicester, UK, pp. 11-95.

15. Akbay T, Demiröz P, Güney Ç. Türkiye'de kan gruplarının coğrafi bölgelere göre dağılımı. GATA Bült. 1989;31:391-402.

16. Alpdemir M, Alpdemir MF, Kocaöz $S$ et al. Balıkesir Bölgesinde $\mathrm{ABO}$ ve Rh Kan Grupları Dağılımı. Balıkesir Sağlık Bil Derg. 2014;3:69-73.

17. Cooling L. Blood Groups in Infection and Host Susceptibility. Clin Microbiol Rev. 2015;28:80170.

18. Neeff M, Biswas K, Hoggard M et al. Molecular Microbiological Profile of Chronic Suppurative Otitis Media. J Clin Microbiol. 2016;54:2538-46.

19. Nurjadi D, Lependu J, Kremsner PG et al. Staphylococcus aureus throat carriage is associated with $\mathrm{ABO}-/$ secretor status. J Infect. 2012;65:310-7.

20. Geisel J, Steuer MK, Ko HL et al. The role of ABO blood groups in infections induced by Staphylococcus saprophyticus and Pseudomonas aeruginosa. Zentralbl Bakteriol. 1995;282:427-30.

21. Steuer MK, Beuth J, Hofstädter F et al. Blood group phenotype determines lectin-mediated adhesion of Pseudomonas aeruginosa to human outer ear canal epithelium. Zentralbl Bakteriol. 1995;282:287-95.

22. Kuo KC, Kuo HC, Huang LT et al. The clinical implications of ABO blood groups in Pseudomonas aeruginosa sepsis in children. $J$ Microbiol Immunol Infect. 2013;46:109-14.

23. Wu O, Bayoumi N, Vickers MA et al. $\operatorname{ABO}(\mathrm{H})$ blood groups and vascular disease: a systematic review and meta-analysis. J Thromb Haemost. 2008;6:62-9.

24. Zhang $\mathrm{W}, \mathrm{Xu}$ Q, Zhuang $\mathrm{Y}$ et al. Novel association of soluble intercellular adhesion molecule 1 and soluble P-selectin with the ABO blood group in a Chinese population. Exp Ther Med. 2016;12:909-14.

25. Mills R, Hathorn I. Aetiology and pathology of otitis media with effusion in adult life. $J$ Laryngol Otol. 2016;130:418-24.

26. Apostolopoulos K, Labropoulou E, Konstantinos $\mathrm{B}$ et al. Blood group in otitis media with effusion. ORL J Otorhinolaryngol Relat Spec. 2002;64:4335.

27. Zang J, Hui L, Yang $\mathrm{N}$ et al. Downregulation of MiR-203a Disinhibits Bmil and Promotes Growth and Proliferation of Keratinocytes in Cholesteatoma. Int J Med Sci. 2018;15:447-55.
28. Chen X, Li X, Qin Z. MicroRNA-21 promotes the proliferation and invasion of cholesteatoma keratinocytes. Acta Otolaryngol. 2016;136:1261-6.

29. Jaff MS. Higher frequency of secretor phenotype in $\mathrm{O}$ blood group- its benefits in prevention and/or treatment of some diseases. Int $J$ Nanomedicine. 2010;5:901-5. 